\title{
Determination of Heat Stress and Ultra Low Oxygen in Chestnut Storage under Control and Modified Atmospheres
}

\author{
Nikos Tzortzakis*, Ioannis Metzidakis \\ Department of Oliviculture and Postharvest Physiology, Institute of Subtropical Plants and Olive Tree of Chania, National Agricul- \\ ture Research Foundation of Greece, Agrokipion, Greece.

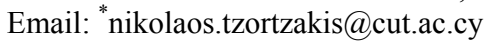

Received November $23^{\text {rd }}, 2011$; revised January $19^{\text {th }}, 2012$; accepted January $26^{\text {th }}, 2012$

\begin{abstract}
The effects of heat stress (HS) and ultra low oxygen (ULO) in controlled (CA) or modified (MA) atmosphere on chestnut (Castanea sativa L. cv. Rodiana) fruit quality and storability were investigated. Chestnuts exposed to ULO $\left(1 \% \mathrm{O}_{2}\right.$ for $1 \mathrm{~h}$ ) or dipped in water bath (at $55^{\circ} \mathrm{C}$ for $15 \mathrm{~min}$ ) and then stored to CA or MA conditions at $6^{\circ} \mathrm{C}$ for up to 90 days. The HS dipping and storage in CA or MA increased sprouting (up to $60 \%$ ) as well as mould severe on chestnuts comparing with the control. In MA conditions, HS and ULO increased respiration rate. Total starch content increased (up to $30 \%$ ) in MA-HS and MA-ULO treatments comparing with the control the first 60 days of storage. The first 30 days of $\mathrm{CA}$ and MA storage, chestnut moisture content decreased. No major differences observed in total sugar, total fat and total phenolic content as well as in the incidence of hole with or without worm in chestnut fruit. Following sensory evaluation, $57 \%$ of panelist marked differences among treatments, while the greater preference $(67 \%)$ observed in chestnut treated with HS and stored in MA. Additionally, MA-HS enhanced (up to 30\%) the chestnut appearance while no difference observed in aroma, sweetness and texture among treatments and storage conditions. Thus, the impacts of HS on chestnuts maintain fruit quality, with benefits in CA storage, as increased panelists' preference.
\end{abstract}

Keywords: Chestnut; Heat Stress; Postharvest; Sensory Evaluation; Ultra Low Oxygen

\section{Introduction}

The chestnut is one of the popular nuts in the oriental world. Raw fresh chestnut is largely utilized by peeling, roasting and boiling, or is processed mainly into syrup packs. The chestnut is rich in carbohydrate and low in fat, with high moisture content and thus it is susceptible to insect damage after harvest [1] with high perishability. The major factors in postharvest depreciation are molding or rotting caused by fungi and the larval development of insects [2,3]. Insect damage is usually due to infestations of Cydia splendana and Curculio elephas, which attack the fruits while still on the trees. Besides insect attack, sprouting normally occurs in chestnut after 2 - 3 months of dormant periods. The chestnut is rich in nutrients (protein 9.3\%, lipid 2.7\%, sugars 7.4\%, amino acids $5.1 \%$ and starch 51.3\%) and has a unique flavor and taste [4].

As a consequence, different treatments have been used to keep the fresh commodities against physiological and biological losses during postharvest periods, such as fu-

${ }^{*}$ Corresponding author. migation $\left(\mathrm{CS}_{2}\right.$, phosphine, methylbromide), low temperature and controlled atmosphere (CA) storage, irradiation, and submerging in icy water for peeled fruit [5]. Most fumigants are very simple to use with a potent efficacy, but have an inherent weakness in terms of their safety. Positively, the United States has proposed that irradiation be used as an alternative treatment for fruits that are host to quarantine pests [6].

Controlled atmospheres have been demonstrated to reduce fungal growth on fruits (as reviewed by Balla and Holb [7]). Additionally, storage under ultra low oxygen (ULO) atmospheres has been shown to suppress development of pathogenic fungi [8] and kill insect pests [9]. Barkai-Golan [8] suggested that refrigerated ULO storage reduced decay by directly suppressing pathogen growth and by indirectly maintaining resistance of the host to infection. They both highlighted the importance of low temperature in combination with ULO for optimum suppression [7]. High temperatures (above $35^{\circ} \mathrm{C}$ ) inhibit ripening of many fruits [10]. The effect of high temperature, applied as heat shock, on inhibition of eth- 
ylene production has been studied in the last few years $[11,12]$. However, this technology may lead to physiological disorders [13]. Other recent preservation methods in development are lyophilization, which results in high-quality products but with high costs, and the combined methods by means of osmotic dehydration and convective air-drying $[14,15]$.

Thus, there is much research in chestnuts preservation against microbes while only few studies focused in fruit quality related parameters $[16,17]$. The present work was to investigate comparative effects of heat stress and ultra low oxygen in controlled and modified atmospheres on the pest control and quality attributes of chestnuts.

\section{Materials and Methods}

\subsection{Plant Material and Treatments}

Chestnut fruit (Castanea sativa L. cv. Rodiana) were hand harvest (in November) for hilly area (Prasses village) of Chania, Creece. Chestnuts (mean average weight $\sim 10$ g) shorted, washed and healthy fruits used for further studies. A sample of 10 fruits was randomly selected to record fruit quality characteristics. A set (72 fruits) of uniform fruits and free of defects were either exposed in low $\mathrm{O}_{2}$ atmospheres (ULO) by subjecting the fruit to a continuous humidified gas flow $\left(60-70 \mathrm{ml} \cdot \mathrm{min}^{-1}\right)$ of $1 \%$ $\mathrm{O}_{2}$ (balance $\mathrm{N}_{2}$ ) for $1 \mathrm{~h}$ at $20^{\circ} \mathrm{C}$ or kept in water bath (HS: heat stress dipping) at a constant temperature of $55^{\circ} \mathrm{C}$ for $15 \mathrm{~min}$. Untreated fruits used as control. Following that, fruits were split in two batches and stored at $6^{\circ} \mathrm{C}$ up to 90 days either in control atmosphere (CA: continuous air flow of $40 \mathrm{ml} \cdot \mathrm{min}^{-1}$ ) in glass vase ( $5 \mathrm{~L}$ capacity) with 3 openings for to achieve the open flow system (one of them was use for gas sampling of $\mathrm{CO}_{2}$ and $\mathrm{O}_{2}$ ) or in modified atmosphere (MA: in commercial sealed bags with $5 \mathrm{~L}$ capacity which were aerated biweekly). Thus the experiments consisted of six treatments ( 3 applications/treatments $\times 2$ storage conditions) with 3 replicates each (36 fruits/replication). Filter paper moistened with water placed into each container, maintaining high relative humidity (RH $\sim 95 \%$ ) during the storage period. Measurements were conducted on biweekly or monthly basis, as analyzed latter on.

\subsection{Decay Evaluation}

Incidence of eye expansion (sprouting), fruit rot decay and brown rot as well as chestnut worm (Lumbricus castaneus) were assessed (up to 36 chestnuts) on a monthly basis. The percentage of external and internal mould and brownish, chestnut with hole but no worm, chestnut with hole and worm and chestnut with expanded eye were evaluated.

\subsection{Water Loss and Respiration Rates of Chestnut}

Healthy (no-infected) chestnuts were labeled and the weight recorded prior to exposure to ambient air or HS or ULO in CA and MA conditions. Fruits were weighed on a monthly basis up to 90 days and percent weight loss of original weight was computed.

Respiration was measured biweekly, automatically by an infrared gas analyzer, as $\mathrm{CO}_{2}$ (SERVOMEX I.R Gas Analyzer PA 404) and $\mathrm{O}_{2}$ (SERVOMEX Oxygen Analyzer 571) production, in the gas phase of the jars.

\subsection{Soluble Sugar, Total Starch, Total Fat Content and Total Phenolic Content of Chestnut}

Soluble sugars contents were determined by Dubois et al. [18] modified method. A $1.0 \mathrm{~g}$ of fresh homogenized tissue were mixed with $5.0 \mathrm{ml}$ aliquot of methanol $(80 \%)$ in glass tubes covered at the top and boiled at $80^{\circ} \mathrm{C}$ for $40 \mathrm{~min}$. After cooling the mixture, a $0.5 \mathrm{ml}$ aliquot of the extract was mixed with $0.5 \mathrm{ml} \mathrm{H} \mathrm{H}_{2} \mathrm{O}$, with $1.0 \mathrm{ml}$ of phenol $(5 \% \mathrm{v} / \mathrm{v})$ and $5.0 \mathrm{ml}$ of concentrated sulfuric acid. After agitation and cooling of the reagent mixture, $\mathrm{A}_{490}$ was read using methanol as blank. Soluble sugars concentration was calculated using sucrose solution as a standard curve.

The remaining chestnut tissue in the glass tubes was used for the total starch content [18]. Thus, $1.2 \mathrm{ml}$ acetate buffer $(0.1 \mathrm{M}$ sodium acetate and $0.1 \mathrm{~N}$ acetic acid; $\mathrm{pH}$ 4.5) was added and then added $0.2 \mathrm{ml}$ enzymes buffer (300 U amyloglucosidase and $25 \mathrm{U}$ amylase) and incubated overnight at $45^{\circ} \mathrm{C}$. Samples were centrifuged and supernatant aliquots were analyzed as above. Total starch content concentration was calculated using sucrose solution as a standard curve.

Total fat extraction was performed according to the published AOAC [19] methods, using a Soxhlet apparatus for $16 \mathrm{~h}$ with petroleum ether as the extraction solvent. The solvent was removed by rotary evaporation and the residue was dried for $1 \mathrm{~h}$ at $105^{\circ} \mathrm{C}$.

Total phenolic concentration was determined (Folin-Ciocalteu Assay, Tzortzakis et al. [20]) from blended fruit (6 individual fruits) tissue extracts $(2.5 \mathrm{~g})$ of following repeated (2-fold) addition of $2.5 \mathrm{ml}$ of $50 \%(\mathrm{v} / \mathrm{v})$ methanol under ultrasonication. Aliquots were collected and centrifuged for $5 \mathrm{~min}$ at $4{ }^{\circ} \mathrm{C}$ at $3000 \mathrm{~g}$. The supernatant was transferred to a fresh Eppendorf tube and 200 $\mu \mathrm{l}$ pipetted into a fresh test tube, to which $1425 \mu \mathrm{l}$ of water (Milli-Q), $125 \mu \mathrm{l}$ of Folin-Ciocalteu's reagent (Sigma Aldrich, Athens, Greece) and $1250 \mu \mathrm{l}$ of $7 \%$ (w/v) sodium carbonate were added. The reaction mix $(3 \mathrm{ml})$ was incubated in the dark for $1.5 \mathrm{~h}$, prior to reading the ab- 
sorbance at $755 \mathrm{~nm}$ (Genesys 10 Vis, ThermoSpectronic, Rochester, USA). Results were expressed in terms of gallic acid equivalents (GAE; Sigma Aldrich, Athens, Greece).

\subsection{Sensory Evaluation}

The tasting panel consisted of a group of 18 people ranging in age from 24 to 60 years old. All panelists had at least some training in the sensory evaluation of chestnuts and chestnuts products. Six chestnuts (three whole and three half-cut chestnuts) of each treatment were placed on a dish for each panelists. The attributes of difference (yes or no), preference, appearance (poor to excellent), sweetness (sharpness to very sweet), texture (soft to hard) and aroma (mild to very strong) were evaluated. Especially for aroma it was noted as vanilla, chestnut, fresh bread, mould, wood and paper. The panelists were asked to indicate their judgment on a 5-point scale. Panel tests were conducted in isolation in booths in the same room to prevent interchange between panel members and without time limit.

\subsection{Statistical Analysis}

Data were first tested for normality, and then subjected to analysis of variance (ANOVA). Sources of variation were time of storage and treatments. Significant differences on percentage values (weight loss) were logarithmic transformed prior to using ANOVA. Statistical analyses were performed using SPSS (SPSS Inc., Chicago, USA) and graphs were produced using Prism v.2.0 (Graph Pad Inc., San Diego, USA).

\section{Results and Discussions}

The moisture content of chestnut fruit before HS or ULO treatments and storage in CA or MA was $55 \%$ with average mean fresh weight $10.3 \mathrm{~g}$ (seed coat weight $1.3 \mathrm{~g}$, endoderm weight $0.7 \mathrm{~g}$ ), total sugars of $36.8 \mathrm{mg} / \mathrm{g}$ fresh weight (fwt), total starch of $39.8 \mathrm{mg} / \mathrm{g}$ fwt, total phenols of $10.2 \mathrm{GAE} / 100 \mathrm{~g}$ fwt, total fats of $1.96 \%$ on dry matter basis.

The HS dipping and storage in CA or MA resulted in increased percentage (from $20 \%$ to $60 \%$ ) of sprouting in chestnuts while no differences observed in the equivalent control treatments and ULO-treated chestnuts. Regarding the incidence of hole with or without worm in chestnut fruit, there were no differences among treatments (data not presented).

The greater percentage of nuts, externally, with moulds as well as the greater mould severe observed in chestnuts treated with HS, which enhanced the mould development, with more effects marked in CA rather than in MA storage (Figure 1). Indeed, an average of $30 \%$ of nuts, in
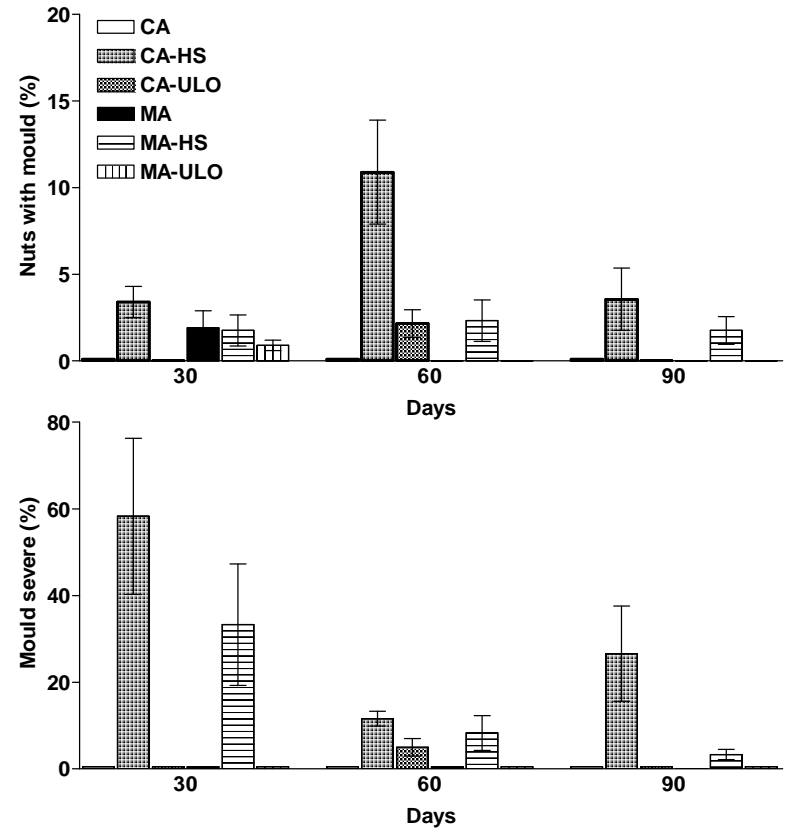

Figure 1. Quantitative (\%) evaluation of nuts with mould development and mould severe in chestnut fruits either treated with heat stress (HS) or ultra low oxygen (ULO) and stored in controlled (CA) or modified (MA) atmospheres up to 90 days at $6^{\circ} \mathrm{C}$. Vertical bars represent standard errors.

ternally, marked mould severe for all the treatments after 60 days of storage (data not presented), and this is due to the long storage period. The microorganisms that macroscopically identified were the fungi of genus Penicillium and Aspergillus and bacteria as well. In previous studies, it was reported that fungal diseases enhanced when chestnut stored in room temperature comparing with low temperature storage [16], with temperature acted as a major factor in disease development. Fungal development was combined with malodor, increased relatively humidity and increased $\mathrm{CO}_{2}$ concentration during chestnut storage [16].

Respiration rates of chestnuts did not differ in fruits stored in CA conditions, while in MA storage, respiration rate increased (69\% and 39\%) through storage period in MA-HS and MA-ULO treated chestnut respectively comparing with the control (MA) fruits, reaching a peak after $75 \mathrm{~d}$ (Figure 2).

ANOVA revealed that moisture content was differentiated (with greater reduction in ULO treated chestnuts) the first 30 days of CA and MA storage (Figure 3). Following 90 days of storage, chestnuts maintained moisture content in CA storage while MA-HS treatments increased (up to 5\%) comparing with MA and MA-ULO. According to Breisch [3], who stated that the humidity content of chestnuts should not be lower than $49 \%$ or higher than $60 \%$ for an adequate conservation, all of the 

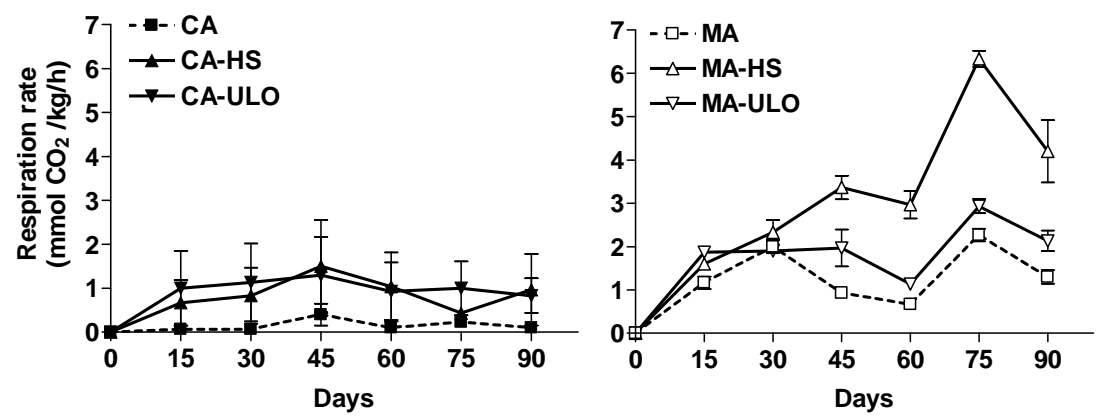

Figure 2. Respiration rate of chestnut fruits either treated with heat stress (HS) or ultra low oxygen (ULO) and stored in controlled (CA) or modified (MA) atmospheres up to 90 days at $6^{\circ} \mathrm{C}$. Vertical bars represent standard errors.
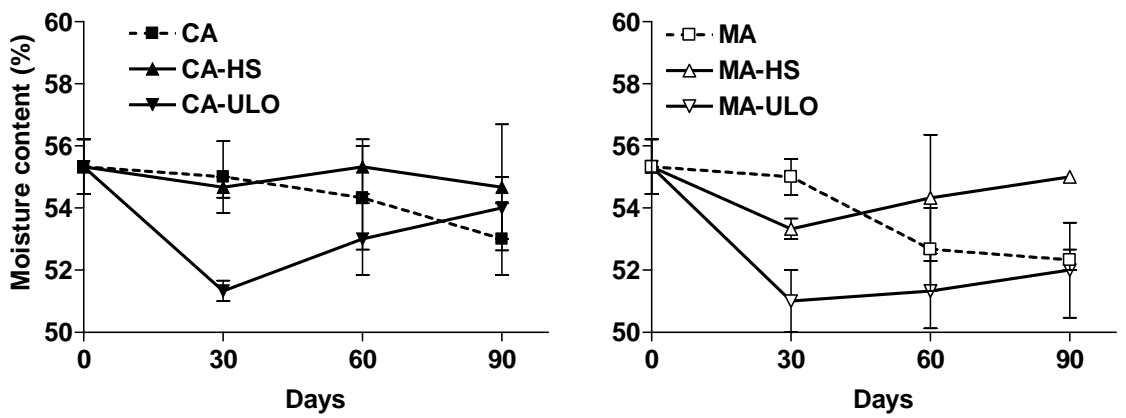

Figure 3. Moisture content of chestnut fruits either treated with heat stress (HS) or ultra low oxygen (ULO) and stored in controlled (CA) or modified (MA) atmospheres up to 90 days at $6^{\circ} \mathrm{C}$. Vertical bars represent standard errors.

measurements had suitable water contents for stability.

No major differences observed in total sugar content among treatments in CA and MA storage (see Figure 4) rather than a stimulate increase through storage period. Indeed, total starch content was significantly $(P<0.05)$ increased/maintained (up to $30 \%$ ) in MA-HS and MAULO treatments comparing with the control the first 60 days of storage but then followed by a substantial reduction at 90 days of storage and resulted in no differences with the control treatment (Figure 4).

The decrease in starch and the constant and concomitant increase in sucrose during storage at low $\left(\right.$ at $\left.1{ }^{\circ} \mathrm{C}\right)$ temperatures were described previously by other workers [21] and is in accordance (comparing with the control treatments) with the present study for the first 60 days of storage, while a steady increase of starch content took place thereafter, which is possible due to different storage conditions and/or variety. However, values of total sugar and starch content are within levels and in accordance with previous reported values in Italy [22].

Although the pathways and the physiological interpretation of the cold- and warm-water bath of chestnuts for starch degradation and sucrose accumulation have not yet been clarified, our results indicate a storage threshold for starch decrease and sucrose increase in the fruits, which probably corresponds to a change in the physiological processes of the nuts, which is in accordance with previ- ous studies [17]. Nomura et al. [21] found no clear correlation between starch decrease, sucrose increase and enzymatic activity in chestnut fruits. It is possible that, as other workers have suggested, the fact that chestnut fruit is a seed, which evolves naturally towards germination, plays a role [3]. During storage at low temperature, physicological processes related to seed respiration, dormancy, postmaturation and germination cannot be excluded [17].

No differences observed in total phenolic content among treatments with exception the slight increased $(13 \%)$ of CA-HS compared with the control (CA) fruits (Figure 5). Additional, the total fat content was more or less similar in fruits exposed to HS or ULO and stored in CA or MA conditions (Figure 6).

Following sensory evaluation, $57 \%$ of panelist marked differences among treatments, while the greater preference $(67 \%)$ observed in chestnut treated with HS and stored in MA, followed with $11 \%$ preference in CA-HS, CA-ULO and MA. Additionally, MA-HS enhanced (up to $30 \%$ ) the appearance of chestnut stored in MA, while no difference observed among chestnut stored in CA under HS or ULO treatment (Table 1). Aroma, sweetness and texture did not differ among treatments and storage conditions. The similarity of sweetness as estimated by the panelists corresponded fairly well with the measured sugar content (Figure 4). 

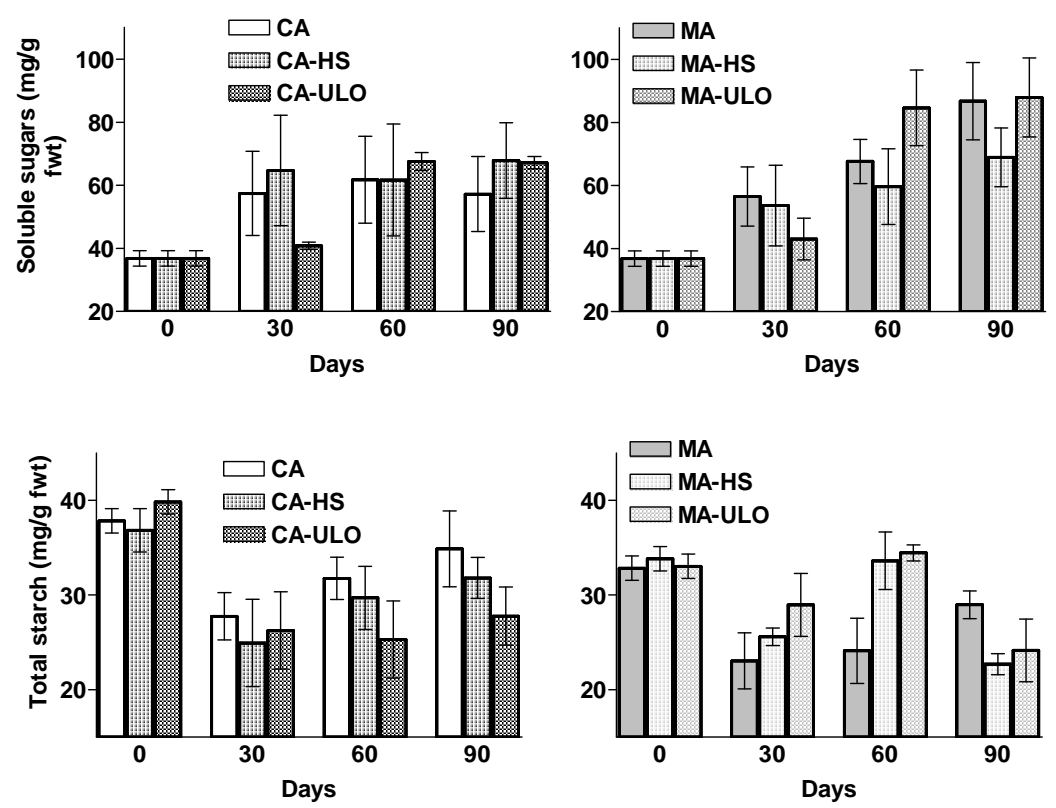

Figure 4. Soluble sugar and total starch content of chestnut fruits either treated with heat stress (HS) or ultra low oxygen (ULO) and stored in controlled (CA) or modified (MA) atmospheres up to 90 days at $6^{\circ} \mathrm{C}$. Vertical bars represent standard errors.
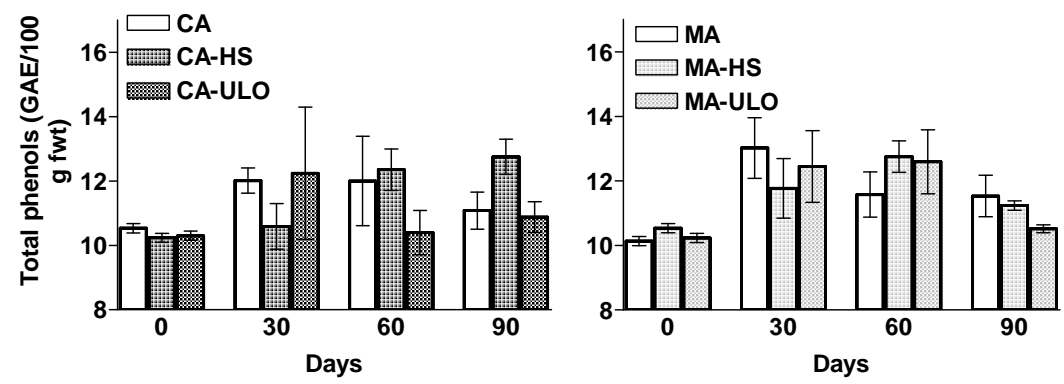

Figure 5. Total phenols content of chestnut fruits either treated with heat stress (HS) or ultra low oxygen (ULO) and stored in controlled (CA) or modified (MA) atmospheres up to 90 days at $6^{\circ} \mathrm{C}$. Vertical bars represent standard errors.
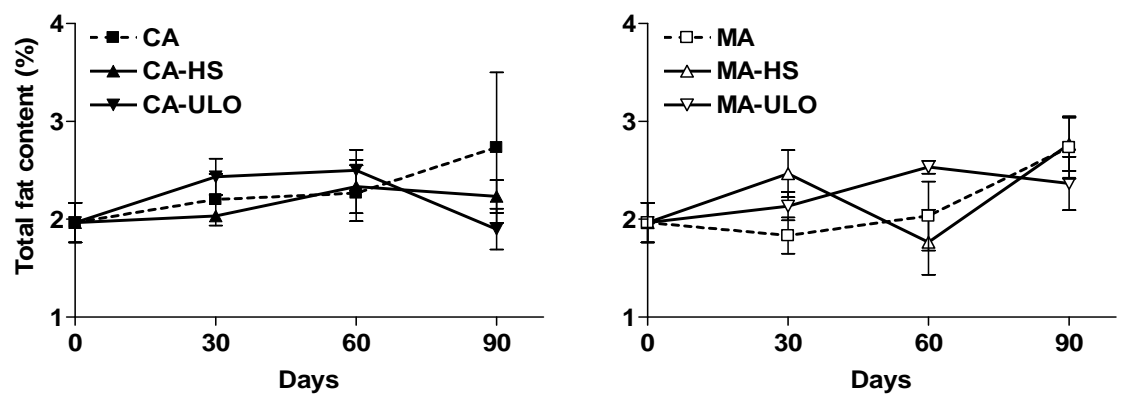

Figure 6. Total fat content of chestnut fruits either treated with heat stress (HS) or ultra low oxygen (ULO) and stored in controlled (CA) or modified (MA) atmospheres up to 90 days at $6^{\circ} \mathrm{C}$. Vertical bars represent standard errors.

Short-term exposure to ultra-low $\mathrm{O}_{2}$ concentrations as a potential quarantine treatment for the control of insects in fruit and vegetables has recently been examined as an alternative to chemical fumigation $[23,24]$. Most fresh fruit and vegetables do not tolerate these low $\mathrm{O}_{2}$ atmos- pheres for prolonged periods, though some can tolerate them for short periods [25]. Low oxygen levels slow the rate of metabolic conversion and maintain fruit quality for longer than normal air storage. Fruit fermentation occurs when ambient oxygen levels fall below some 
Table 1. Quantitative analysis of the impacts of heat stress (HS) or ultra low oxygen (ULO) on sensory attributes of chestnut fruits following storage in controlled (CA) or modified (MA) atmospheres up to 90 days at $6{ }^{\circ} \mathrm{C}$ and $95 \% \mathrm{RH}$. Values represent mean of assessments made by 18 panelists per treatment.

\begin{tabular}{cccccc}
\hline & Preference & Appearance & Aroma & Sweetness & Texture \\
\hline CA & $0 \mathrm{c}$ & $50 \mathrm{~b}$ & $43 \mathrm{a}$ & $53 \mathrm{a}$ & $74 \mathrm{a}$ \\
CA-HS & $11 \mathrm{~b}$ & $59 \mathrm{~b}$ & $54 \mathrm{a}$ & $50 \mathrm{a}$ & $74 \mathrm{a}$ \\
CA-ULO & $11 \mathrm{~b}$ & $49 \mathrm{~b}$ & $46 \mathrm{a}$ & $57 \mathrm{a}$ & $71 \mathrm{a}$ \\
MA & $11 \mathrm{~b}$ & $53 \mathrm{~b}$ & $45 \mathrm{a}$ & $61 \mathrm{a}$ & $71 \mathrm{a}$ \\
MA-HS & $67 \mathrm{a}$ & $76 \mathrm{a}$ & $52 \mathrm{a}$ & $60 \mathrm{a}$ & $73 \mathrm{a}$ \\
MA-ULO & $0 \mathrm{c}$ & $63 \mathrm{ab}$ & $38 \mathrm{a}$ & $54 \mathrm{a}$ & $69 \mathrm{a}$ \\
\hline
\end{tabular}

In each column, mean values followed by the same letter do not differ significantly at $\mathrm{P}=0.05$ according to Duncan's MRT.

critical level, which is typically shown by an increase in respiratory quotient (RQ: the ratio of moles of $\mathrm{CO}_{2}$ produced divided by moles of $\mathrm{O}_{2}$ utilized), ethanol production, or both [26]. Undesirable responses include the induction of fermentation, development of disagreeable flavors, reduction in aroma biosynthesis, induction of tissue injury and alteration in the makeup of microbial flora $[27,28]$.

In previous studies, under CA storage maintained chestnut quality for longer period in low temperature and ULO conditions, resulting in lower chestnut mould [16] while the low temperature comparing with room temperature, is the main factor that affect chestnut quality.

\section{Conclusion}

The impacts of HS on chestnuts before storage revealed greater respiration rates, increased panelists preference but with a slightly higher infection percentage comparing with the other treatments/storage and it may considered for chestnut preservation technique, especially the under CA storage conditions. However, further exploitation is needed before commercial applications.

\section{REFERENCES}

[1] K. Tanaka, K. Kotobuki and N. Kakiuchi, "Numerization of Peeling Easiness and Role of Phenolic Compounds of the Pellicle in the Adhesion between the Pellicle and Embryo in Comparison of Japanese (Castanea crenata Sief. et Zucc.) and Chinese Embryo (Castanea mollissima Blume) Chestnuts," Journal of the Japanese Society for the Horticultural Science, Vol. 50, 1981, pp. 363-371. doi:10.2503/jishs.50.363

[2] J. M. Wells and J. A. Payne, "Mycoflora and Market Quality of Chestnuts Treated with Hotwater to Control the Chestnut Weevil," Plant Disease, Vol. 64, 1980, pp 999-1001. doi:10.1094/PD-64-999

[3] H. Breisch, "Harvest, Storage and Processing of Chestnuts in France and Italy," In: E. Antognozzi, Ed., Interna- tional Congress on Chestnuts, University of Perugia, Spoleto, 20-23 October 1993, pp. 429-436.

[4] J. Xu, "The Effect of Low-Temperature Storage on the Activity of Polyphenol Oxidase in Castanea henryi Chestnuts," Postharvest Biology and Technology, Vol. 38, No. 1, 2005, pp. 91-98. doi:10.1016/j.postharvbio.2005.05.011

[5] J. H. Kwon, J. Lee, S. B. Lee, H. S. Chung and J. U. Choi, "Effects of Water Soaking and Gamma Irradiation on Storage Quality of Chestnuts," Korean Journal of Postharvest Science and Technology, Vol. 89, 2001, pp. 9-15.

[6] USDA/APHIS, "Use of Irradiation as a Quarantine Treatment for Fresh Fruits of Papaya from Hawaii," Federal Register, Vol. 54, 1989, pp. 387-393.

[7] B. Balla and I. Holb, "Effect of Three Storage Methods on Fruit Decay and Brown Rot of Apple," International Journal of Horticultural Science, Vol. 13, 2007, pp. 55-57.

[8] R. Barkai-Golan, "Postharvest Disease Suppression by Atmospheric Modifications," In: M. Calderon and R. Barkai-Golan, Eds., Food Preservation by Modified Atmospheres, CRC Press, Boca Raton, pp. 237-264.

[9] C. Ke and A. A. Kader, "Potential of Controlled Atmospheres for Postharvest Insect Disinfestation of Fruits and Vegetables," Postharvest News Information, Vol. 3, 1991, pp. 31-37.

[10] F. G. Mitchell, "Influence of Cooling and Temperature Maintenance on Stone Fruit Quality," Deciduous Fruit Grower, Vol. 36, 1986, pp. 205-211.

[11] S. Lurie and J. D. Klein, "Heat Treatment of Ripening Apples: Differential Effects on Physiology and Biochemistry," Physiologia Plantarum, Vol. 78, 1990, pp. 181186. doi:10.1111/j.1399-3054.1990.tb02078.x

[12] S. Lurie and J. D. Klein, "Acquisition of Low Temperature Tolerance in Tomatoes by Exposure to High-Temperature Stress," Journal of the American Society for the Horticultural Science, Vol. 116, No. 6, 1991, pp. 1007- 1012 .

[13] J. C. Pech, C. Balague, A. Latche and M. Bouzayen, "Postharvest Physiology of Climacteric Fruits: Recent Developments in the Biosynthesis and Action of Ethyl- 
ene," Sciences des Aliments, Vol. 14, 1994, pp. 3-15.

[14] F. Chenlo, R. Moreira, C. Fernandez-Herrero and G. Vazquez, "Mass Transfer during Osmotic Dehydration of Chestnut Using Sodium Chloride Solutions," Journal of Food Engineering, Vol. 73, No. 2, 2006, pp. 164-173. doi:10.1016/j.jfoodeng.2005.01.017

[15] F. Chenlo, R. Moreira, C. Fernandez-Herrero and G. Vazquez, "Experimental Results and Modelling of the Osmotic Dehydration Kinetics of Chestnut with Glucose Solutions," Journal of Food Engineering, Vol. 74, No. 3, 2006, pp. 324-334. doi:10.1016/j.jfoodeng.2005.03.002

[16] S. Nour-Eldin, D. Gerasopoulos and I. Metzidakis, "Effects of Storage Conditions on Chestnuts Quality," Postharvest Physiology, Pathology and Technologies for Horticultural Commodities: Recent Advances, Agadir Morocco, 1995, pp. 196-201.

[17] M. Jermini, M. Conedera, T. N. Sieber, A. Sassella, H. Scharer, G. Jelmini and E. Hohn, "Influence of Fruit Treatments on Perishability during Cold Storage of Sweet Chestnuts," Journal of the Science of Food and Agriculture, Vol. 86, No. 6, 2006, pp. 877-885. doi:10.1002/jsfa. 2428

[18] M. Dubois, K. A. Gilles, J. K. Hamilton, P. A. Rebers and F. Smith, "Colorimetric Method for the Determination of Sugars and Related Substances," Analytical Chemistry, Vol. 28, No. 3, 1956, pp. 350-356. doi:10.1021/ac60111a017

[19] AOAC, "Official Methods of Analysis of AOAC International," 17th Edition, Association of Official Analytical Chemists, USA, 2000.

[20] N. Tzortzakis, A. Borland, I. Singleton and J. Barnes, "Impact of Atmospheric Ozone-Enrichment on QualityRelated Attributes of Tomato Fruit," Postharvest Biology and Technology, Vol. 45, No. 3, 2007, pp. 317-325. doi:10.1016/j.postharvbio.2007.03.004
[21] K. Nomura, Y. Ogasawara, H. Uemukai and M. Yoshida, "Change of Sugar Content in Chestnut during Low Temperature Storage," Acta Horticulturae, Vol. 398, 1995, pp. 265-276.

[22] E. Bellini, E. Giordani, C. Marinelli and B. Perucca, "Marrone del Mugello PGI Chestnut Nutritional and Organoleptic Quality," Acta Horticulturae, Vol. 693, 2005, pp. 97-102.

[23] A. Carpenter and M. Potter, "Controlled Atmospheres," In: J. L. Sharp and G. J. Hallman, Eds., Quarantine Treatments for Pests of Food Plants, Westview Press, Boulder, 1994, pp. 171-198.

[24] E. J. Mitcham, S. Zhou and A. A. Kader, "Potential of CA for Postharvest Insect Control in Fresh Horticultural Perishables," Proceedings of the Seventh International Controlled Atmosphere Research Conference, 13-18 July 1997, University of California, Davis, pp. 78-90.

[25] C. Ke and A. A. Kader, "External and Internal Factors Influence Fruit Tolerance to Low-Oxygen Atmospheres," Journal of the American Society for the Horticultural Science, Vol. 117, No. 6, 1992, pp. 913-918.

[26] E. Pesis, "The Role of the Anaerobic Metabolites, Acetaldehyde and Ethanol, in Fruit Ripening, Enhancement of Fruit Quality and Fruit Deterioration," Review Postharvest Biology and Technology, Vol. 37, No. 1, 2005, pp. 119. doi:10.1016/j.postharvbio.2005.03.001

[27] M. Meheriuk, B. Girard, L. Moyls, H. J. T. Beveridge, D. L. McEnzie, J. Harrison, S. Weintraub and R. Hocking, "Modified Atmosphere Packaging of 'Lapins' Sweet Cherry," Food Research International, Vol. 28, No. 3, 1995, pp. 239-244. doi:10.1016/0963-9969(95)00003-5

[28] R. M. Beaudry, "Effect of $\mathrm{O}_{2}$ and $\mathrm{CO}_{2}$ Partial Pressure on Selected Phenomena Affecting Fruit and Vegetable Quality," Postharvest Biology and Technology, Vol. 15, No. 3, 1999, pp. 293-303. doi:10.1016/S0925-5214(98)00092-1 